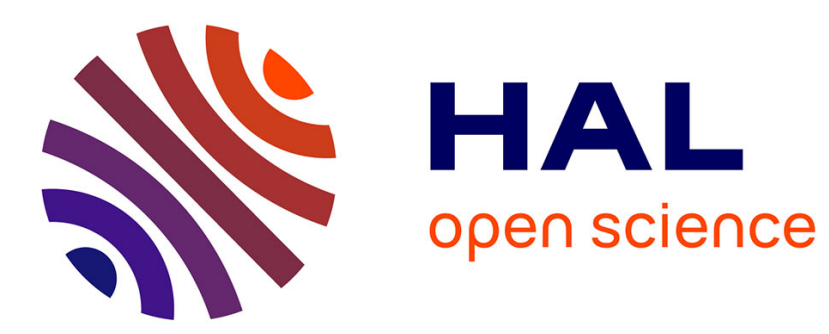

\title{
The effect of natural pozzolan on delayed ettringite formation of the heat-cured mortars
}

van Huong Nguyen, Ali-Nordine Leklou, Jean-Emmanuel Aubert, Pierre Mounanga

\section{- To cite this version:}

van Huong Nguyen, Ali-Nordine Leklou, Jean-Emmanuel Aubert, Pierre Mounanga. The effect of natural pozzolan on delayed ettringite formation of the heat-cured mortars. Construction and Building Materials, 2013, 48, pp.479-484. 10.1016/j.conbuildmat.2013.07.016 . hal-01007361

\section{HAL Id: hal-01007361 https://hal.science/hal-01007361}

Submitted on 21 Oct 2018

HAL is a multi-disciplinary open access archive for the deposit and dissemination of scientific research documents, whether they are published or not. The documents may come from teaching and research institutions in France or abroad, or from public or private research centers.
L'archive ouverte pluridisciplinaire HAL, est destinée au dépôt et à la diffusion de documents scientifiques de niveau recherche, publiés ou non, émanant des établissements d'enseignement et de recherche français ou étrangers, des laboratoires publics ou privés. 


\title{
The effect of natural pozzolan on delayed ettringite formation of the heat-cured mortars
}

\author{
Van-Huong Nguyen ${ }^{\mathrm{a}, \mathrm{b}}$, Nordine Leklou ${ }^{\mathrm{a}, *}$, Jean-Emmanuel Aubert ${ }^{\mathrm{c}}$, Pierre Mounanga ${ }^{\mathrm{a}}$ \\ ${ }^{a}$ LUNAM Université, Université de Nantes - IUT Saint-Nazaire, GeM, CNRS UMR 6183, Research Institute in Civil Engineering and Mechanics, France \\ ${ }^{\mathrm{b}}$ Water Resource Engineering Department, Danang University of Technology, Viet Nam \\ ' Université de Toulouse, UPS, INSA, LMDC (Laboratoire Matériaux et Durabilité des Constructions), 135, avenue de Rangueil, F-31 077 Toulouse Cedex 04, France
}

H I G H L I G H T S

- The use of finer pozzolan in partial replacement of cement controlled or even eliminated the DEF expansion.

- The substitution of cement with coarse pozzolan is not only ineffective but even accelerated the DEF expansion.

- The DEF was correlated with the evolution of the mass, compressive strength, elastic modulus and porosity of the specimens.

\section{A B S T R A C T}

Delayed Ettringite Formation (DEF) is an internal sulfate attack caused by early age heating to a temper-ature of over $70{ }^{\circ} \mathrm{C}$. In this paper, the effect of natural Algerian pozzolan on the expansion of cement mor-tars caused by DEF was investigated. For this purpose, a portion of cement was replaced by natural pozzolan, with three different dosages (10\%, 20\% and 30\%) and finenesses (fine, medium, and coarse). The results obtained highlighted the significant effects of natural pozzolan on DEF and the correlation existing between the expansion of the heat-cured mortars and the evolution of their mechanical properties.

\section{Introduction}

Delayed Ettringite Formation (DEF) is an internal sulfate attack caused by heat-induced decomposition of ettringite formed during the initial hydration of cement at elevated temperature (above about $70^{\circ} \mathrm{C}$ ) and its re-crystallization in the hardened matrix [13]. This reaction is a physico-chemical phenomenon inducing an expansion of the cement paste that could lead to cracking of concrete. These cracks result in a decrease of the mechanical performances and durability parameters of the material. Highlighted in the middle of $1980 \mathrm{~s}$, this pathology exists in most parts of the world and has become one of the major problems for the durability of concrete structures and precast concrete elements, causing significant and costly damages.

The use of pozzolanic additives in partial substitution of cement may be an efficient way to prevent concrete from internal sulfate attack. Indeed, pozzolanic reactions enable to reduce the amount

\footnotetext{
* Corresponding author. Tel.: +33 (0)240178641; fax: +33 (0)240178160

E-mail address: nordine.leklou@univ-nantes.fr (N. Leklou).
}

of calcium hydroxide in the material, improving the sulfate resistance of the material [4]. Ramlochan et al. [5] showed that the use of silica fume in replacement of cement by up to $8 \%$ did not control the long-term expansion related to DEF. However, the beginning of the expansion was delayed due to the low permeability of mortars incorporating silica fume. Besides, the use of a small proportion ( $8 \%$ ) of metakaolin could prevent the long-term expansion related to DEF. This was attributed to the high content of $\mathrm{Al}_{2} \mathrm{O}_{3}$ in metakaolin and the effect of the reduction leaching of the alkali hydroxide from the pore fluid. Indeed, the microstructure was showed that the outer $\mathrm{C}-\mathrm{S}-\mathrm{H}$ gel appeared less fibril and the cement matrix was less porous at earlier ages with use of metakaolin or silica fume. The microanalytical evidence suggests that monosulfate was finely intermixed with the $\mathrm{C}-\mathrm{S}-\mathrm{H}$ gel in the outer product at the end of the heat treatment. In specimens that expanded during moist storage at ambient temperature this monosulfate was replaced by ettringite, which initially formed also on a fine scale intermixed with the $\mathrm{C}-\mathrm{S}-\mathrm{H}$ gel in the outer product. With the incorporation of a sufficient amount of an $\mathrm{Al}_{2} \mathrm{O}_{3}$-bearing mineral admixture this did not appear to occur. For fly ash, the 
quantity required to eliminate the expansion depends on its composition. Fly ash with a low concentration in lime seems to work better with low rates of substitution (15-25\%) while fly ash with a high concentration in lime could be effective at higher replacement levels (25-35\%). For blast furnace slag, the substitution rate needed to eliminate the long-term expansion with the majority of the cements was about 25\%, but higher levels may be required for cements with very high sulfate or alkali contents. More recently, according to data recorded on 12-month specimens, Atahan and Dikme [4] reported that different mineral additives, including nano (colloidal) silica, micro silica, fly ash and ground granulated blast furnace slag showed a significant mitigation of expansion due to internal sulfate attack. Particularly, the efficiency of nanosilica in limiting the expansions caused by internal sulfate attack was found to be highly significant when used in very low substitution rate of cement (4-6\%). This result can be attributed to both its very high surface area $\left(>80,000 \mathrm{~m}^{2} / \mathrm{kg}\right)$ and purity $\left(>99 \% \mathrm{SiO}_{2}\right)$.

Moreover, the technical guide [6] for the prevention of disorders due to delayed ettringite recommends to use cements with low heat of hydration in accordance with standard NF EN 197-1/ A1, such as blended cements (CEM II to CEM V) or binary binders prepared with CEM I and pozzolanic additions.

Nevertheless, there are still very few studies on the effects of natural pozzolanic additions on the development of DEF. In this context, the experimental study presented in this paper focuses on characterizing the influence of the fineness and dosage of natural pozzolan and the effects of the storage conditions of mortars on the risk of occurrence of DEF.

\section{Experimental study}

\subsection{Materials and experimental program}

The cement used in this study was a CEM I 52.5 N CE CP2 NF from Couvrot plant (France). The volcanic tuft used for this study was an Algerian natural pozzolan, extracted from the Bouhamidi deposit in the Beni-Saf region (north-west of Algeria). The volcanic tufts were received in rock form and were crushed to obtain three different finenesses (fine pozzolan: PzF, medium pozzolan: PzM and coarse pozzolan: PzC). 0/2-mm siliceous sand with a density of $2600 \mathrm{~kg} / \mathrm{m}^{3}$ was used for the preparation of mortars. This sand meets standard NF EN 196-1 specifications [7] and is classified as non-reactive with respect to alkali-silica reaction (standard NF-P 18590 [8]). Siliceous sand was chosen because it leads to faster expansion than limestone sand [9].

The mortars were prepared according to NF EN 196-1 standards [7], with three different pozzolan dosages (10\%, $20 \%$ and $30 \%)$. Considering the binder content as the sum of cement and pozzolan dosages, each mortar was mixed with a binder/ sand weight ratio $(B / S)$ of $1 / 3$ and a total water/binder ratio $\left(W_{t} / B\right)$ of 0.56 . Their composition is detailed in Table 1 . The amount of added water in Table 1 corresponds to the mass of mixing water directly introduced in the mixer bowl, whereas the amount of total water takes into account both the mass of mixing water and the natural water content of pozzolan. In order to accelerate and amplify the appearance of expansion, $3.1 \%$ (by weight of binder) of sodium sulfate $\left(\mathrm{Na}_{2} \mathrm{SO}_{4}\right)$ were added to the mortars $[10,11]$. It was dissolved in the mixing water before introduction in the mixer bowl.

Mortars were cast under the form of $40 \times 40 \times 160 \mathrm{~mm}^{3}$ prisms in steel moulds, equipped with brass studs to measure the specimen expansion. The moulds were thus readily covered with a plastic plate to prevent evaporation and the mor-

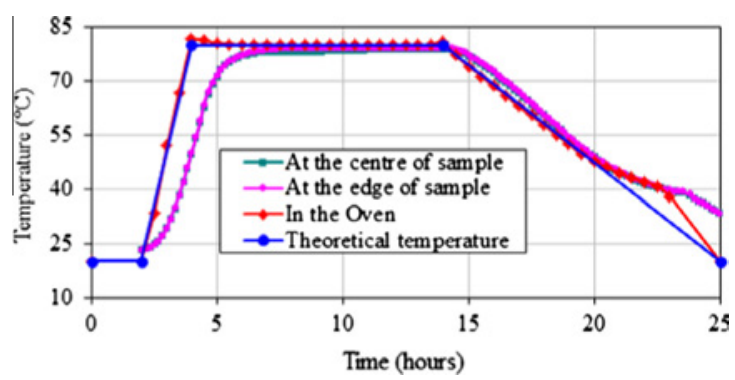

Fig. 1. Heat treatment applied to the mortar samples.

tars were submitted to a four-stage heat treatment (Fig. 1). They were initially cured for $2 \mathrm{~h}$ at $20^{\circ} \mathrm{C}$. The temperature was then increased to $80^{\circ} \mathrm{C}$ at a rate of $30^{\circ} \mathrm{C}$ per hour. The temperature was maintained at $80^{\circ} \mathrm{C}$ for $10 \mathrm{~h}$, and finally decreased during $11 \mathrm{~h}$ to reach $20^{\circ} \mathrm{C}$. Thermocouples were placed in the oven, at the center and the edge of the sample to record the temperatures reached during the treatment.

The specimens were then removed from the moulds and stored in closed tanks containing deionised water at $20^{\circ} \mathrm{C}$. Two storage conditions were considered. In the first case (denoted "NRW": Non-Renewed Water), the bath water was not renewed during the whole period test. In the second case (denoted "RW": Renewed Water) the water was regularly renewed: it was changed weekly up to 8 weeks; then; every 2 weeks up to 24 weeks and finally every 4 weeks until the end of the test period.

\subsection{Testing methods}

The particle size distribution of the materials was measured using laser diffraction with a CILAS $1180 \mathrm{~L}$ apparatus. XRD patterns were done by using an X-ray diffractometer SEIFERT MZ VI E with Co K $\alpha$ radiation. Measures were done on the bulk powdered samples.

The pozzolanic activity was determined by the method of $\mathrm{Ca}(\mathrm{OH})_{2}$ depletion in lime-pozzolan paste [12,13]. This method is based on the decomposition of crystalline calcium hydroxide into calcium oxide and water in a temperature range from $400{ }^{\circ} \mathrm{C}$ to $600^{\circ} \mathrm{C}$ by thermogravimetric analysis (TGA). Lime-pozzolan paste was performed by combining $50 \%$ natural pozzolan and $50 \% \mathrm{Ca}(\mathrm{OH})_{2}$ powder in presence of enough water to give a normal consistency paste. The fresh pastes were filled into the plastic bottles to prevent moisture loss and carbonation, and then the bottles were stored in the room at $20{ }^{\circ} \mathrm{C}$ and at relative humidity of $50 \%$. The amount of reacted lime in the lime-pozzolan pastes for a specific age ( 7 and 28 days), was calculated from the difference between the initial and the final amount of free lime that was determined by a TGA/DSC1 device of Mettler Toledo company in a static air nitrogen with heating rate $5{ }^{\circ} \mathrm{C} / \mathrm{min}$ from $25^{\circ} \mathrm{C}$ to $800^{\circ} \mathrm{C}$. Before to realize the TGA and to accelerate the pozzolanic reaction, the paste bottles were cured at $50{ }^{\circ} \mathrm{C}$ for $24 \mathrm{~h}$. The pozzolanic activity is expressed as percent of the ratio of reacted lime amount to initial lime amount.

The evolutions of length, mass, elastic dynamic modulus and compressive strength of the specimens were measured over a test period of more than 450 days.

The length and mass measurements were performed in the air using an extensometer and a balance with a resolution of $\pm 1 \mu \mathrm{m}$ and $\pm 0.01 \mathrm{~g}$, respectively. The first measurements were carried out $24 \mathrm{~h}$ after the casting. For each mortar and for each curing condition, the average expansion and the mass variation were obtained from three different specimens. These specimens were then used to determine the dynamic Young's modulus ( $\left.E_{\mathrm{dyn}}\right)$ and the compressive strength $\left(R_{\mathrm{c}}\right)$ of each mortar $E_{\text {dyn }}$ was measured by non-destructive impulse excitation tests using a Grindosonic $^{\circledR}$ apparatus. The mortar prisms were elastically struck at half length. The flexura and torsional resonant frequency of the productive signal were recorded by a vibration sensor. Finally, $E_{\mathrm{dyn}}$ is determined from the frequencies, geometric dimensions

Table 1

Mortar mix proportions.

\begin{tabular}{|c|c|c|c|c|c|c|c|c|c|c|}
\hline \multirow[t]{3}{*}{ Reference } & \multicolumn{10}{|l|}{ Components } \\
\hline & \multirow[t]{2}{*}{ Cement (g) } & \multirow[t]{2}{*}{ PzF (g) } & \multirow[t]{2}{*}{ PzM (g) } & \multirow[t]{2}{*}{$\mathrm{PzC}(\mathrm{g})$} & \multirow[t]{2}{*}{ Sand (g) } & \multirow[t]{2}{*}{$\mathrm{Na}_{2} \mathrm{SO}_{4}(\mathrm{~g})$} & \multicolumn{2}{|c|}{ Water added } & \multicolumn{2}{|c|}{ Total water } \\
\hline & & & & & & & Mass (g) & $\mathrm{W}_{\mathrm{a}} / \mathrm{B}$ & Mass (g) & $\mathrm{W}_{\mathrm{t}} / \mathrm{B}$ \\
\hline Ref. & 450 & - & - & - & 1350 & 13.95 & 252 & 0.56 & 252.00 & 0.560 \\
\hline PzF30 & 315 & 135 & - & - & & & & & 262.46 & 0.597 \\
\hline PzM10 & 405 & - & 45 & - & & & & & 254.73 & 0.570 \\
\hline PzM20 & 360 & - & 90 & - & & & & & 257.47 & 0.579 \\
\hline РzM30 & 315 & - & 135 & - & & & & & 260.20 & 0.589 \\
\hline PzC30 & 315 & - & - & 135 & & & & & 258.34 & 0.582 \\
\hline
\end{tabular}


and the mass of the sample. The compressive strength was determined on pieces of half prisms that result from flexural strength tests (European standard NF EN 196-1 [7]). Each data reported represents the average value obtained from six compressive strength tests.

The porosity and pore size distribution were measured by mercury intrusion porosimetry (MIP) on mortar fragments. These fragments were first dried in an oven at $40{ }^{\circ} \mathrm{C}$ with silica gel until their mass was stabilized. This takes about 14 days. The AutoPore IV 9500 apparatus (which is capable of a maximum intruding pressure of $228 \mathrm{MPa}$ ) was used, so that the pore radius ranges from $2.5 \mathrm{~nm}$ to $180 \mu \mathrm{m}$. The contact angle of $130^{\circ}$ and the surface tension of mercury of $0.485 \mathrm{~N} /$ $\mathrm{m}$ were used in the computations.

\section{Results and discussion}

\subsection{Characteristics of cement and pozzolan}

The chemical compositions of the cement and pozzolan were given in Table 2. Application of Bogue's formulas to the chemical composition of the cement gave the following mass distribution for the main phases: $66 \%$ of $\mathrm{C}_{3} \mathrm{~S}, 13 \%$ of $\mathrm{C}_{2} \mathrm{~S}, 11 \%$ of $\mathrm{C}_{3} \mathrm{~A}, 7 \%$ of $\mathrm{C}_{4} \mathrm{AF}$ and gypsum content of $6 \%$.

The natural pozzolan was essentially composed of silica and alumina (more than $60 \%$ ); a previous study reported that, depending on the extraction area, it could contain around $87 \%$ of these two oxides [14]. All elements were in the range typical for natural pozzolans (Table 2 [15-18]) but the $\mathrm{SiO}_{2}$ content, essentially responsible for the pozzolanic activity, was close to the lower limit. XRD study showed that this rock was composed of volcanic glass and crystallized minerals, mainly quartz, feldspars and pyroxene (Fig. 2).

The particle size distributions of the materials under study are shown in Fig. 3: cement and PzF exhibited a quite similar particle size distribution; the PzM and the PzC were coarser. Indeed, at the cumulative passing percentage of $50 \%$ the diameter size of $\mathrm{PzC}$ and of PzM were $188 \mu \mathrm{m}$ and $47 \mu \mathrm{m}$ respectively, whereas this diameter size is equal to $22 \mu \mathrm{m}$ for PzF. This difference is clearer if the Blaine fineness is considered. It should be noted that the fineness of the natural pozzolan significantly affected the pozzolanic activity.

Physical properties and pozzolanic activity of the different finenesses of pozzolan are indicated in Table 3. The results show a clear relationship between the pozzolanic activity and the fineness of natural pozzolan. Indeed, the pozzolan activity increases with the fineness increasing.

\subsection{Effects of pozzolan and curing conditions on DEF}

Figs. 4-6 present the expansion curves of the different mortars. These curves were assembled into three plots in order to highlight the effect of pozzolan fineness (Fig. 4), of pozzolan content (Fig. 5) and of curing conditions under water (Fig. 6) on the development of mortar expansion. The expansion limit $(0.04 \%)$ specified by NF P 18-585 standards [19] and the recommendation by LCPC [6] has been added in each graph.

Table 2

Chemical composition of cement and pozzolan.

\begin{tabular}{|c|c|c|}
\hline Components (\%) & Cement & Pozzolan \\
\hline Silica $\left(\mathrm{SiO}_{2}\right)$ & 19.5 & 46.8 \\
\hline Alumina $\left(\mathrm{Al}_{2} \mathrm{O}_{3}\right)$ & 5.2 & 17.5 \\
\hline Ferric oxide $\left(\mathrm{Fe}_{2} \mathrm{O}_{3}\right)$ & 2.3 & 8.4 \\
\hline Calcium oxide $(\mathrm{CaO})$ & 64.2 & 9.4 \\
\hline Magnesium oxide (MgO) & 0.9 & 3.9 \\
\hline Sulfuric anhydride $\left(\mathrm{SO}_{3}\right)$ & 3.5 & 0.4 \\
\hline Titanium dioxide $\left(\mathrm{TiO}_{2}\right)$ & 0.3 & - \\
\hline Potassium oxide $\left(\mathrm{K}_{2} \mathrm{O}\right)$ & 1.07 & 1.40 \\
\hline Sodium oxide $\left(\mathrm{Na}_{2} \mathrm{O}\right)$ & 0.07 & 4.32 \\
\hline Chlorine $\left(\mathrm{Cl}^{-}\right)$ & 0.01 & 0.03 \\
\hline Loss on ignition & 2.4 & 4.8 \\
\hline
\end{tabular}

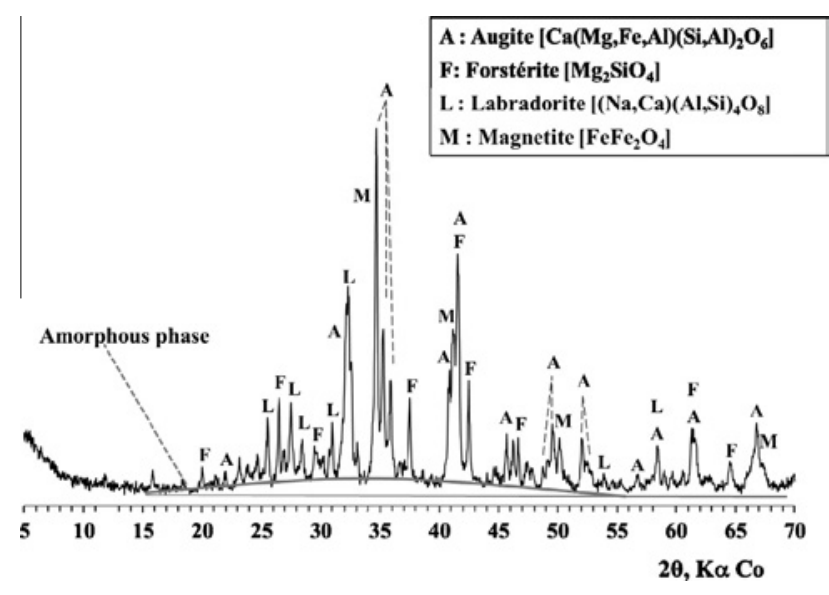

Fig. 2. DRX diffractogram of the pozzolan.

The general S-shape of the expansion curves was very similar to that observed by Ramlochan et al. [5] on cement mortars cured at 80 and $95^{\circ} \mathrm{C}$. Three main phases could be distinguished: an induction phase characterized by very small deformations, followed by a phase of fast expansion and finally a plateau of deformations.

The time and the magnitude of these different phases were directly influenced by the fineness and the dosage in pozzolan and the curing conditions of the specimens.

Fig. 4 presents the expansion curves of mortars containing $30 \%$ of pozzolan with different degrees of fineness and kept in non-renewed water for 491 days. The coarser pozzolan gave the faster expansion, by both reducing of the induction period and increasing of the expansion rate of the second phase, when compared with the reference mortar. The PzC30-NRW mortar reached its plateau of expansion after about 70 days. The increase of the pozzolan fineness had a positive effect on the limitation of expansion due to the DEF. The PzM30-NRW mortar showed a longer induction period than the PzC30-NRW mortar and a slower ultimate expansion than the PzC30-NRW and Ref-NRW mortars. The PzF30-NRW mortar did not exhibit visible expansion within the investigation period. Finer pozzolan was therefore more efficient to mitigate or even eliminate expansion, by consuming more portlandite, releasing quickly $\mathrm{Al}_{2} \mathrm{O}_{3}$ and binding more alkalis than coarser pozzolan $[4,5]$. Indeed, the releasing quickly $\mathrm{Al}_{2} \mathrm{O}_{3}$ leads to the reduction of $\mathrm{SO}_{3} / \mathrm{Al}_{2} \mathrm{O}_{3}$ ratio and therefore reduces the potential for expansion of the DEF [2]. On the other hand, the consumption of the hydration product $\left(\mathrm{Ca}(\mathrm{OH})_{2}\right)$ by the pozzolanic reaction increase with the increasing in fineness of pozzolan (Table 3 ), this leads to the reducing $\mathrm{pH}$ of the pore solution followed by the decrease of the concentration $\mathrm{SO}_{4}^{2-}$ in the pore solution therefore absorption of sulfate by $\mathrm{C}-\mathrm{S}-\mathrm{H}$ during heat treatment can be reduced [22] and the potential for expansion of the DEF is reduced. It is worth noting that all the samples made with natural pozzolan had smaller ultimate deformation than the reference specimens. This effect can be attributed to the beneficial influence of pozzolanic reactions and the reduction of sulfate content due to the partial substitution of cement with pozzolan.

Fig. 5 presents the expansion curves of mortars prepared with $10 \%, 20 \%$ and $30 \%$ of medium pozzolan. It was observed that, for all the replacement level considered, the onset of expansion of the blended cement mortars occurred sooner than that of the reference mortar and they reached the ultimate expansion plateau earlier than the control mortar. The increase in pozzolan content from $10 \%$ to $20 \%$ accelerated the onset of expansion of sample, this but did not persist with the increase in pozzolan content from $20 \%$ to $30 \%$. Indeed, the expansion beginnings of the PzM10-NRW, PzM20-NRW and PzM30-NRW are at 55 days, 30 days and 45 days 

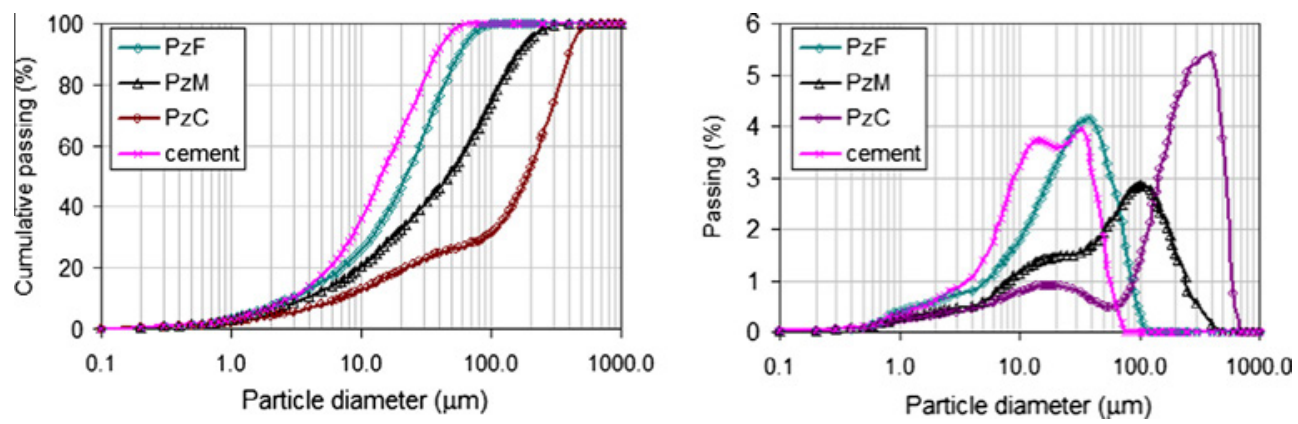

Fig. 3. Particle size distribution curves of the pozzolans and cement.

Table 3

Physical properties of materials and pozzolanic activity of pozzolan.

\begin{tabular}{llllll}
\hline Characteristics & Cement & \multicolumn{3}{l}{ Pozzolan } \\
\cline { 4 - 6 } & & PzF & PzM & PzC \\
\hline Physical characteristics & & & & \\
Real density $\left(\mathrm{g} / \mathrm{cm}^{3}\right)$ & 3.09 & 2.43 & 2.51 & 2.55 \\
Water content $(\%)$ & - & 8.40 & 6.47 & 4.93 \\
Blaine specific area $\left(\mathrm{cm}^{2} / \mathrm{g}\right)$ & & 4000 & 3710 & 1768 & 1235 \\
Pozzolanic activity & 7 days & - & 33.6 & 25.6 & 14.8 \\
$\mathrm{Ca}(\mathrm{OH})_{2}$ consumption $(\%)$ & 28 days & - & 43.6 & 30.5 & 17.1 \\
\hline
\end{tabular}

respectively. This onset of expansion is due to the competition between the decrease in strength and stiffness of mortars when the pozzolan dosage increased (this loss of mechanical performances may be favorable for development of DEF) and the decrease in sulfate content (unfavorableness for development of DEF) due to the increase of pozzolan substitution. Nevertheless, replacing $20 \%$ and $30 \%$ of cement with pozzolan was found to be effective at controlling long-term expansion: the 491-days expansion values of PzM20-NRW and PzM30-NRW mortars were respectively 14\% and $63 \%$ lower than that of the reference mortar. These results show that, for the experimental conditions considered here, the content of natural pozzolan control the long-term expansion due to DEF.

Fig. 6 shows the effect of the curing conditions (in renewed or non-renewed water) on the expansive behavior of the specimens. The mortars kept in renewed water developed faster and higher expansions than mortars stored in non-renewed water which confirms previous results $[20,21]$. Indeed, renewing water enhanced hydrous and ionic transfers, which influenced both the appearance and development of DEF. Firstly, the increase of the mobility of aluminate and sulfate ions contained in the mortars favoured the formation of ettringite. Secondly, the ionic transfers accelerated the leaching of alkalis, modifying the chemical balance of the pore solution by decreasing the concentration of alkalis. This decrease of alkalis in the pore solution, and consequently, of its $\mathrm{pH}$, induced liberation of sulfates from the CSH as shown by Divet and Diamond
$[22,23]$. This was favorable for the formation of ettringite and could explain why the expansion was almost accelerated in renewed water.

\subsection{Relationship between expansion, mass variation, porosity and mechanical properties}

In order to establish the relationship between the expansive behavior and the mass variation of a mortar and the evolution of its mechanical and microstructural properties, the porosity, compressive strength, dynamic Young's modulus and the mass variation of the PzM20-RW mortar were measured and analyzed. The evolution of the properties of PzM20-RW mortar (which was stored in renewed water for 393 days) is presented in Fig. 7.

During the induction period of the DEF, the ettringite was deposited in the available pore space and has not produced significant expansion. The specimens began to expand after about 21 days, and expanded by $0.1 \%$ at about 50 days. This low initial swelling was followed by an accelerated phase of expansion until about 154 days, preceding a plateau with an ultimate expansion value of about $1.35 \%$. On the other hand, the mass variation curve shows a sudden and rapid increase in the mass at the early age due to the penetration of water into the initial capillary porosity of the mortar. Then, it follows the same trend as the expansion curve. This correlation indicates that the mass variation of the specimen is directly linked to the formation of ettringite, which induced cracks and supplementary porosity in the mortar. This leads to an increase in the amount of absorptive water in the porous network. The correlation mentioned above was confirmed with the mercury porosity results, which firstly showed a decrease of porosity in the early days (due to both the hydration process and the formation of delayed ettringite as microcrystals dispersed in the C-S-H gel [24]) and then an increase of porosity (related to the accelerated expansion and the development of cracks in the mortar). This porosity evolution is clearly confirmed if the pore size distribution is considered, being the incremental mercury intruded expressed as a function of the pores diameter (Fig. 8). Indeed, at

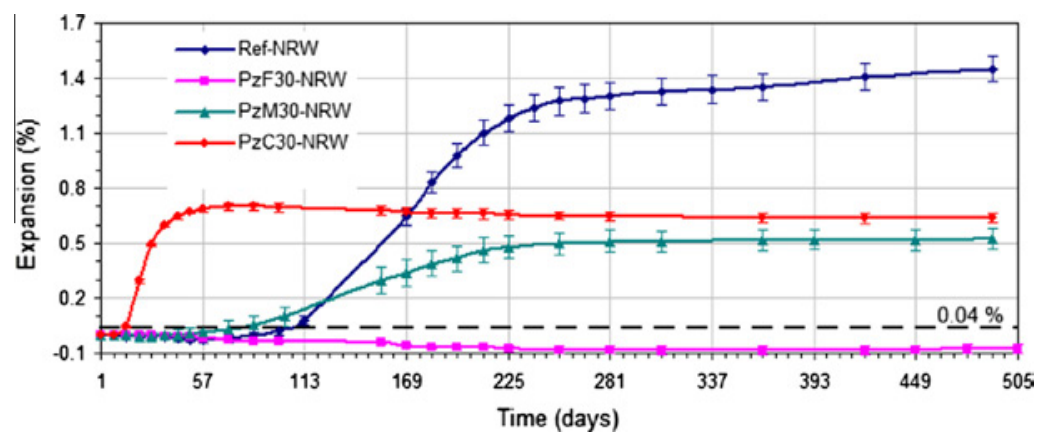

Fig. 4. Expansion of mortars prepared with different fineness of pozzolan (non-renewed water). 


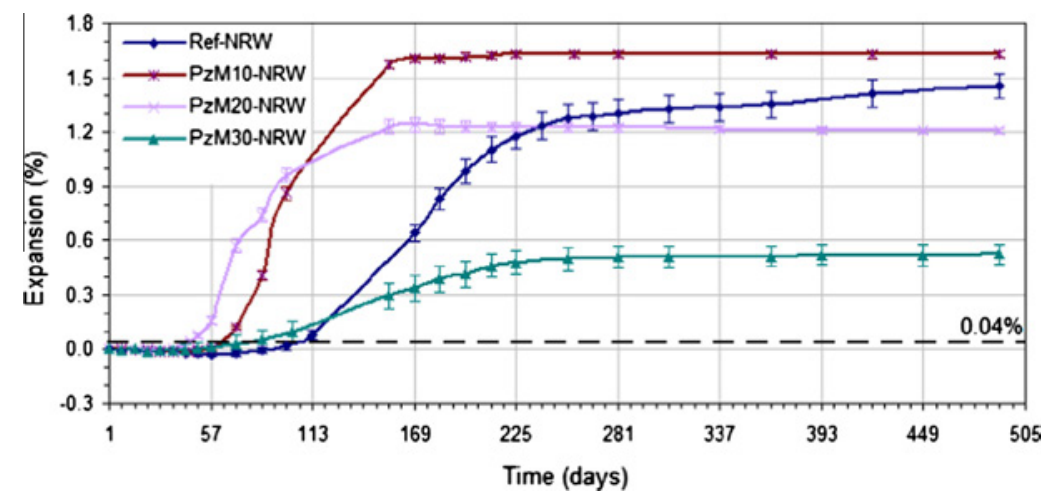

Fig. 5. Expansion of mortars prepared with different contents of medium pozzolan (non-renewed water).

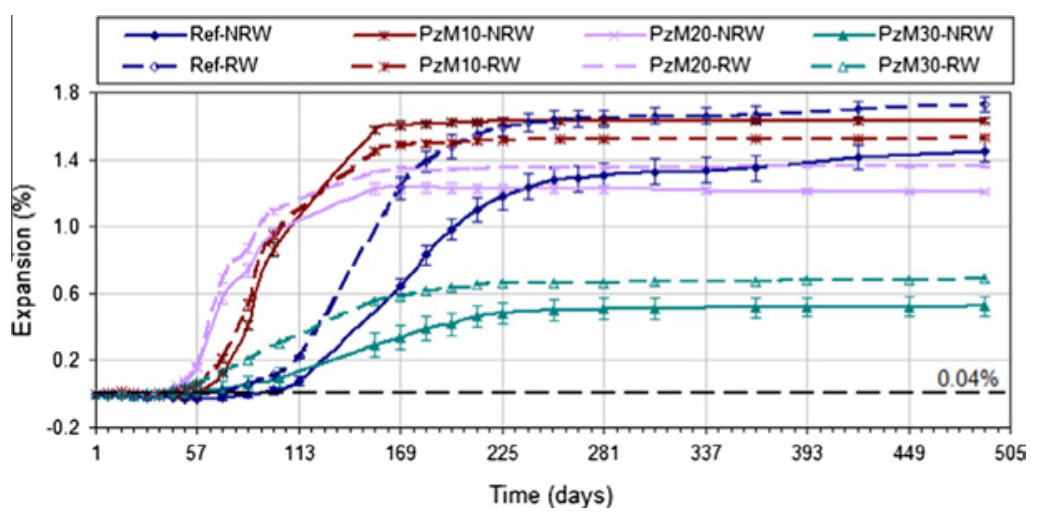

Fig. 6. Expansion of mortars prepared with different contents of medium pozzolan (renewed and non-renewed water).

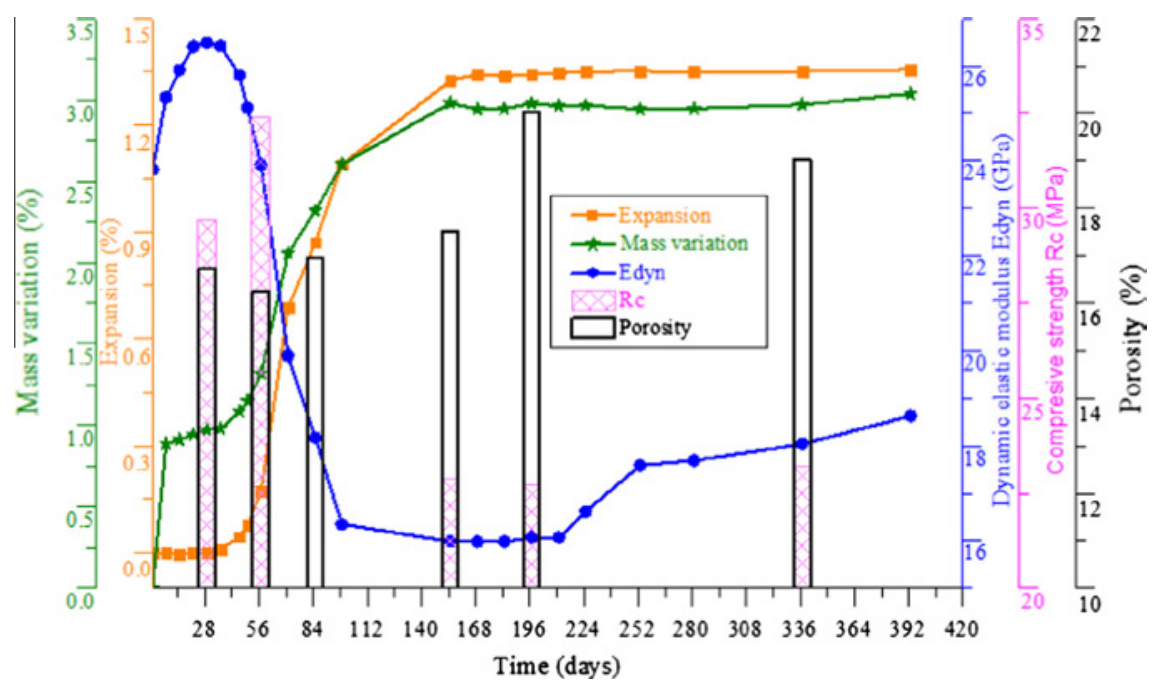

Fig. 7. Expansion, mass variation, dynamic elastic modulus, compressive strength and porosity versus time for the PzM20-RW mortar.

29 days, no expansion, the distribution curve exhibits a single peak at $600 \AA$, and then when the expansion begins developed theirs distribution curves appear the second peak at around $9000 \AA$. These peaks shift toward the larger diameter with expansion increasing due to DEF.

Finally, Fig. 7 shows an increase of both the compressive strength and the dynamic elastic modulus of the mortar during the induction period, followed by a dramatic drop of these two properties corresponding to the phase of accelerated expansion, as observed by Zhang et al. [25]. Notice however that the rapid decrease of the dynamic elastic modulus and the compressive strength was compensated by the gradual increase of these properties in the long term when the expansion phenomenon slowed down. These late increases were probably due to both a later for- 


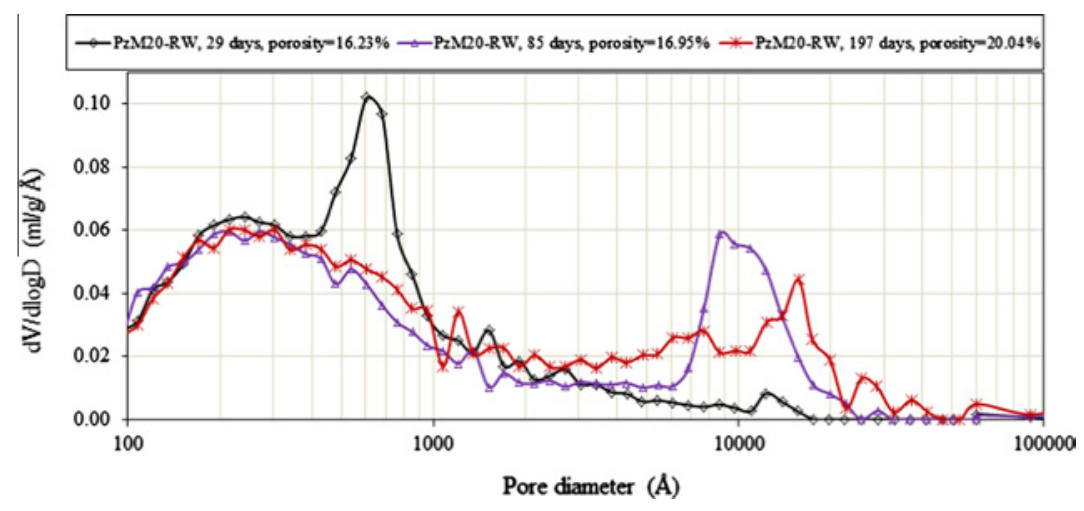

Fig. 8. The evolution of pore distributions of PzM20-RW mortar.

mation of ettringite in the voids and the late hydration of anhydrous cement grains put in contact with water during the (micro) cracking process [3].

\section{Conclusions}

This research work focused on the effect of natural pozzolan on the expansive behavior of heat-cured cement-based mortars subjected to DEF. From the analysis of the results obtained, the following conclusions can be drawn:

- The fineness of natural pozzolan significantly affected the expansion rate of mortars. The use of finer pozzolan in partial replacement of cement controlled or even eliminated the DEF expansion. This positive effect was explained by the higher pozzolanic activity of fine pozzolan particles. At the contrary, the substitution of cement with coarse pozzolan was not only ineffective but even accelerated the DEF expansion.

- The development of DEF in mortars was correlated with the evolution of the mass, compressive strength, dynamic elastic modulus and porosity of the specimens. This correlation resulted from a competition between three mechanisms: on the one hand, the hydration process and the filling of the initial porosity by re-crystallized ettringite, which caused a decrease of porosity and an increase of the mechanical performances, and, on the other hand, the pressure exerted by the growth of ettringite crystals on the pore walls, which caused cracks and supplementary porosity in mortar, resulting in a drop of compressive strength and elastic modulus of the specimens.

\section{References}

[1] Collepardi M. A state-of-the-art review on delayed ettringite attack on concrete. Cem Concr Compos 2003;25(4-5):401-7.

[2] Taylor HFW, Famy C, Scrivener KL. Delayed ettringite formation. Cem Concr Res 2001;31(5):683-93.

[3] Pavoine A, Brunetaud X, Divet L. The impact of cement parameters on delayed ettringite formation. Cem Concr Compos 2012;34(4):521-8.

[4] Atahan HN, Dikme D. Use of mineral admixtures for enhanced resistance against sulfate attack. Constr Build Mater 2011;25(8):3450-7.

[5] Ramlochan T, Zacarias P, Thomas MDA, Hooton RD. The effect of pozzolans and slag on the expansion of mortars cured at elevated temperature. Part I: Expansive behaviour. Cem Concr Res 2003;33(6):807-14.
[6] LCPC. Recommendations for preventing disorders due to delayed ettringite formation. Guide technique of the laboratoires des ponts et chaussées; 2009.

[7] AFNOR NF EN 196-1. Method of testing cement. Part 1: Determination of strength; 2006.

[8] AFNOR NF-P 18-590. Essai accéléré de stabilité dimensionnelle sur mortier.

[9] Yang R, Lawrence CD, Sharp JH. Effect of type of aggregate on delayed ettringite formation. Adv Cem Res 1999;11(3):119-32.

[10] Escadeillas G, Aubert JE, Segerer M, Prince W. Some factors affecting the delayed ettringite formation of heat-cured mortars. Cem Concr Res 2007;37(10):1445-52.

[11] Leklou N, Aubert JE, Escadeillas G. Microscopic observations of samples affected by the delayed ettringite formation (DEF). Mater Struct 2009;42:1369-78.

[12] Uzal B, Turanlı L, Yücel H, Göncüoğlu MC, Çulfaz A. Pozzolanic activity of clinoptilolite: a comparative study with silica fume, fly ash and a non-zeolitic natural pozzolan. Cem Concr Res 2010;40(3):398-404.

[13] Pourkhorshidi AR, Najimi M, Parhizkar T, Jafarpour F, Hillemeier B. Applicability of the standard specifications of ASTM C618 for evaluation of natural pozzolans. Cem Concr Compos 2010;32(10):794-800.

[14] Belas Belaribi N, Semcha M, Laoufi L. Influence of the Beni-Saf pozzolana on the mechanical characteristics of the concretes. Can J Civ Eng 2003;30(3):580-4 [in French].

[15] Hewlett P. Lea's chemistry of cement and concrete. Pozzolana and pozzolanic cements. Oxford: Elsevier Science \& Technology Books; 2004. p. 471-635 [chapter 10].

[16] Cook DJ. Natural pozzolans. In: Swamy RN, editor. Concrete technology and design, cement replacement materials, vol. 3. Surrey University Press; 1986 [chapter 1].

[17] ACI (American Concrete Institute). Use of raw or processed natural pozzolans in concrete, ACI Committee 232, manual of concrete practice ACI 232.1R-00; 2000.

[18] Segui P, Aubert JE, Husson B, Measson M. Utilization of a natural pozzolan as main component of hydraulic road binder. Constr Build Mater 2013;40:217-23.

[19] AFNOR NF P 18-585. Granulats - Stabilité dimensionnelle en milieu alcalinEssai sur mortier. Expérimentale décembre; 1990.

[20] Aubert JE, Escadeillas G, Leklou N. Expansion of five years old mortars attributable to DEF: relevance of the laboratory studies on DEF? Constr Build Mater 2009;23(12):3583-5.

[21] Aubert JE, Escadeillas G, Leklou N. Five year monitoring of curing solutions of heat-cured mortars affected by DEF. Adv Cem Res 2013;25(1). http:// dx.doi.org/10.1680/adcr.11.00069.

[22] Divet L, Randriambololona R. Delayed ettringite formation: the effect of temperature and basicity on the interaction of sulfate and $\mathrm{C}-\mathrm{S}-\mathrm{H}$ phase. Cem Concr Res 1998;28(3):357-63.

[23] Diamond S. The relevance of laboratory studies on delayed ettringite formation to DEF in field concretes. Cem Concr Res 2000;30(12):1987-91.

[24] Taylor H.F.W. Sulfate reactions in concrete - microstructural and chemical aspects, Cement Technology (Ceramic Transactions), vol. 40, 1989, p.61-78, Westerville, $\mathrm{OH}$.

[25] Zhang Z, Olek J, Diamond S. Studies on delayed ettringite formation in earlyage, heat-cured mortars: I. Expansion measurements, changes in dynamic modulus of elasticity, and weight gains. Cem Concr Res 2002;32(11):1729-36. 